\title{
掺 $\mathrm{Cr}$ 和掺 $\mathrm{Pr}$ 的 $\mathrm{Bi}_{4} \mathrm{Ge}_{3} \mathrm{O}_{12}$ 晶体的 线性光伏效应 ${ }^{* 1)}$
}

\author{
马锡淇 程朝阳 2) 殿之文 胡关钦
}

(中国科学院上海硅酸盐研究所, 上海 200050)

关键词光伏效应、掺杂 $\mathrm{Bi}_{4} \mathrm{Ge}_{3} \mathrm{O}_{12}$ 晶体、Glass 常数

锗酸铋 $\mathrm{Bi}_{4} \mathrm{Ge}_{3} \mathrm{O}_{12}$ ( $\mathrm{BGO}$ ) 属于立方晶系, $43 m$ 点群, 是硅铋矿 $\mathrm{Bi}_{4} \mathrm{Si}_{3} \mathrm{O}_{12}$ ( $\mathrm{BSO}$ ) 的同型晶 体. BGO 晶体也是一种极好的闪柏材料, 用于高能粒子或射线的探测. 此外, Moya 等报道 了 $\mathrm{BGO}: \mathrm{Cr}$ 是一种很有希望的光折变材料 ${ }^{[1]}$.

本文报道两种掺杂 $\mathrm{BGO}$ 晶体 (BGO: $\mathrm{Cr}$ 和 $\mathrm{BGO}: \mathrm{Pr}$ ) 在杂质吸收区的线性光伏效应 的实验结果,并根据 Fridkin 提出的 PVE 极化涨落模型进行了初步讨论 ${ }^{[2]}$.

\section{一、实验}

BGO 晶体是由上海硅酸盐研究所用 Bridgeman-Stockbarger 方法生长的. 先从熔融的 纯度 $5 \mathrm{~N}$ 的 $\mathrm{Bi}_{2} \mathrm{O}_{3}$ 和 $6 \mathrm{~N}$ 的 $\mathrm{GeO}_{2}$ 混合物中生长出大晶体, 两种组分的摩尔比是 $2: 3$. 然后;

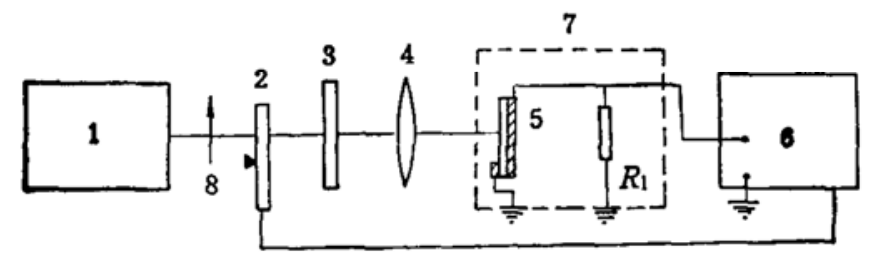

图 1 用锁相放大器测量光伏电流

1.㴪铇灯，2.斩波器，3.誌光片，4.透镜，5.样品，

6. 锁相放大器, 7. 搌敝缺, 8. 偏振片 以该晶体为原料, 掺以不同的杂质.掺杂 浓度分别为 $0.025 \mathrm{wt} \%\left(\mathrm{Cr}_{2} \mathrm{O}_{3}\right)$ 和 0.2 wt \% $\left(\mathrm{Pr}_{2} \mathrm{O}_{3}\right)$. 长成的 $\mathrm{BGO}: \mathrm{Cr}$ 和 BGO:Pr 分别呈绿色和黄绿色, 颜色分 布均匀. 垂直于 [010] 轴从大块晶体上 切出样品. 样品两面抛光, 光炤面涂以 氧化铟锡 (ITO) 透明电极, 背面为烧 银电极. 样品厚度 $2 \mathrm{~mm}$, 面积 $1 \mathrm{~cm}^{2}$ 左

右. 光吸收谱采用 Shimadzu UV $-265^{\circ}$ 自动分光光度计测量.

图 1 是线性光伏电流测量装置图，其中考虑到合成线性光伏电流方向为垂直于样品受光 面. 从 $250 \mathrm{~W}$ 卤铇灯发出的白光, 先经偏振片成为线偏拢光, 再经 $400 \mathrm{~Hz}$ 的调制后, 经滤色 片成为准单色光, 照射于样品 (010)面上. 光线经扩束以使光斑均匀覆盖整个样品表面, --.个 高值电阻 $R_{l}$ 与样品的一对电极相联, 输人锁相放大器以检测线性光伏电流. 它阻 $R_{l}$ 远小 于晶体体电阻,因此光伏效应是在短路条件下测量的. 所有实验均于室海下进行.

1992-01-20 收稿, 1992-05-30 收修改槅

* 国家自然科学基金资助项目

1) 上海父通大学应用物理系 87 级李浩参加了部分工作

2) 现在机电部 51 研究所工作 


\section{二、实验结果和讨论}

图 2 和图 3 是 $\mathrm{BGO}: \mathrm{Cr}, \mathrm{BGO}: \mathrm{Pb}$ 和 $\mathrm{BGO}: \mathrm{Pr}$ 的光吸收谱. 掺 $\mathrm{Cr}$ 的 $\mathrm{BGO}$ 从 $580 \mathrm{~nm}$ 到 BGO 光吸收边呈宽带吸收. 该宽带包 括 3 个未分解的吸收带, 分别位于 $520 \mathrm{~nm}$, $440 \mathrm{~nm}$ 以及 1 个与吸收边重叠的高能带. 另外，长波区还可看到有 3 个峰重叠而成 的吸收带. 掺 $\operatorname{Pr}$ BGO 的吸收谱包括了 $\mathrm{Pr}^{3+}$ 离子的几个特征吸收谱, 其中与主要 谱线对应的电子跃迁为 ${ }^{3} \mathrm{H}_{4}-{ }^{3} \mathrm{P}_{2}(435 \mathrm{~nm})$, ${ }^{3} \mathrm{H}_{4}-{ }^{1} \mathrm{I}_{6},{ }^{3} \mathrm{P}_{1}(465 \mathrm{~nm}),{ }^{4} \mathrm{H}_{4}-{ }^{3} \mathrm{P}_{0}$ (480nm) 以 及 ${ }^{3} \mathrm{H}_{4}-{ }^{1} \mathrm{D}_{2}(580,590,605 \mathrm{~nm})$. 光吸收系 数 $\boldsymbol{\alpha}$ 根据样品的界面反射率进行了修正.

由 $\mathrm{Bi}_{3} \mathrm{Ge}_{4} \mathrm{O}_{12}$ 所属的 $\overline{4} 3 \mathrm{~m}$ 点群可知: 其结构对称性具有 3 个 2 次轴和 3 个 4 次 反转轴(均沿基矢方向), 以及 4 个 3 次轴.

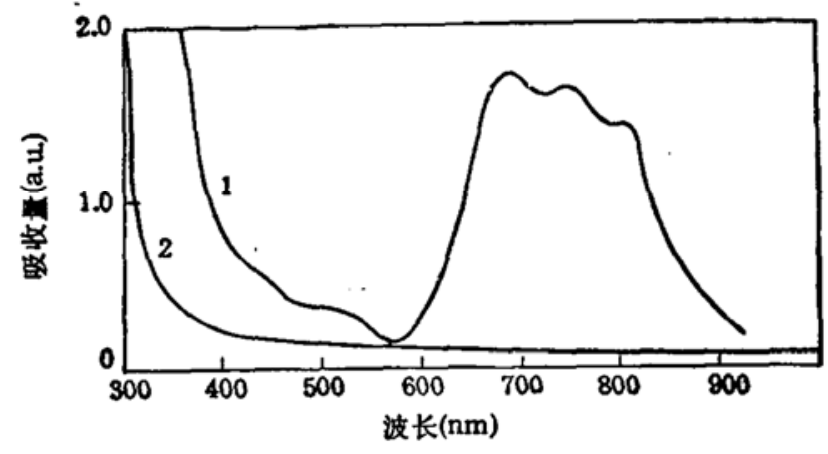

图 2 BGO: $\mathrm{Cr}$ 和 BGO: $\mathrm{Pb}$ 的光吸收谱 1一一室温下掺铬 $\mathrm{Bi}_{4} \mathrm{Ge}_{3} \mathrm{O}_{12}$ 晶体的光吸收谱, 2 - 掺铅 $\mathrm{Bi}_{4} \mathrm{Ge}_{3} \mathrm{O}_{12}$ 晶体的室温光吸收谱, 它 实际上与纯晶体相同 容易证明,其三阶线性光伏张量只有 3 个相等的非零元素, 即 $\beta_{14}-\beta_{25}-\beta_{360}$. 当光线以(010) 方向入射时,

$$
\left(J_{\mathrm{LPV}}\right),-I \beta_{14} \sin 2 \theta,
$$

其中 $\theta$ 为偏振方向与 $(100)$ 或 $(001)$ 轴(即 $x$ 轴或 $z$ 轴)的夹角, $I$ 是光强.

实验发现掺 $\mathrm{Cr}$ 和掺 $\mathrm{Pr}$ 的 BGO 存在线性光伏电流. 图 4 表明白光照射下 BGO:Cr 晶 体线性光伏电流对人射光偏振方向的依赖. 它是正弦关系, 与(1)式一致. 从图中还可以看到

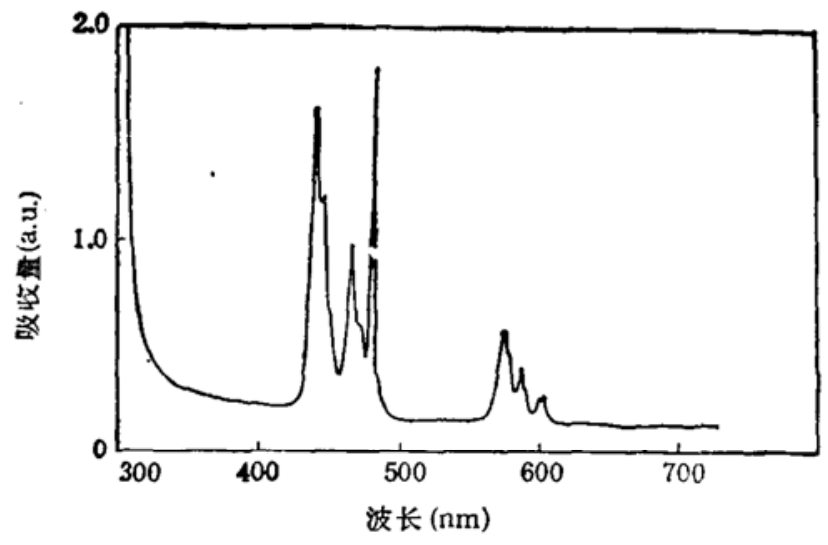

图 3 掺虂 $\mathrm{Bi}_{4} \mathrm{Ge}_{3} \mathrm{O}_{12}$ 晶体的室温光吸收橧

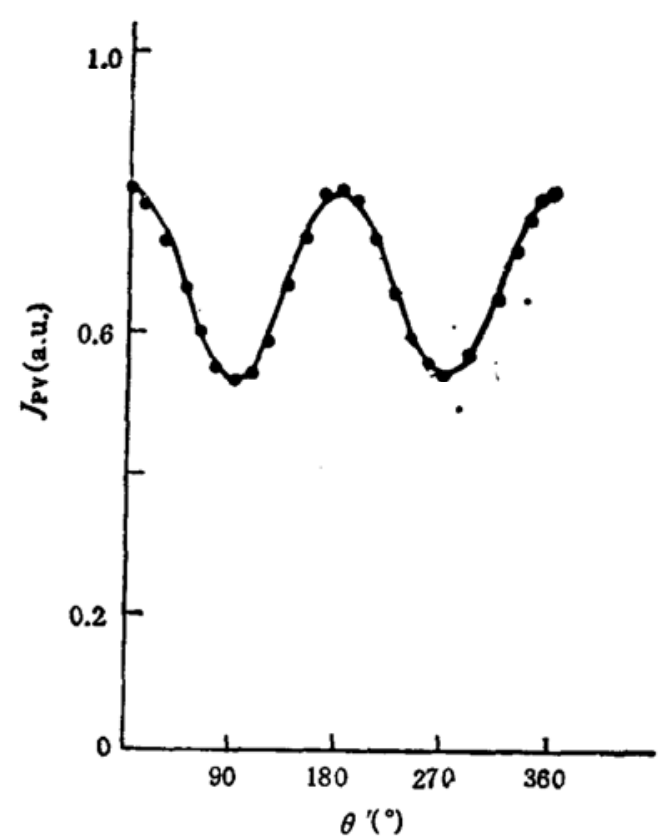

图 4 掺铬 $\mathrm{Bi}_{4} \mathrm{Ge}_{3} \mathrm{O}_{12}$ 晶体中线性光伏电流 与偏振方向的关系(白光)

$\theta^{\prime}$ 是偏振方向与起始偏振方向的夹角, 不同于式(1)中的 $\theta, \theta^{\prime}=\theta+\theta$. 
总的光伏电流大于星正弦变化的线性光伏电流, 另外这部分不随 $\theta$ 变化的光伏电流起因尚不 清楚, 可能来自电极与 $\mathrm{BGO}$ 的接触部分, 类似半导体/金属接触电势.

Glass 等曾发现短路光伏电流 $J_{P_{\mathbf{V}}}$ 与对应的光强度 $I$ 严格成正比. 可以表示为

$$
J_{\mathrm{PV}}-K_{\mathrm{G}} \cdot \alpha \cdot I,
$$

其中 $\boldsymbol{\alpha}$ 是光吸收系数. 比例常数 $K_{\mathrm{G}}$ 称为 Glass 常数. 它与吸收中心的性质有关. 另外,人 们还发现许多材料如过渡金属掺杂的 $\mathrm{LiNbO}_{3}$ 中, $K_{0}$ 随波长减小而增加 ${ }^{[3]}$. 我们的实验中 也发现 BGO: $\mathrm{Cr}$ 和 $\mathrm{BGO}: \mathrm{Pr}$ 的光伏电流呈现相当明显的波长依赖. 虽然目前精确测量 $\mathrm{BGO}: \mathrm{Cr}$ 和 BGO: $\mathrm{Pr}$ 线性光伏电流的光谱曲线尚有一定困难, 但是, 可以指出, 可测量的线性 光伏电流仅出现在几个特定的杂质吸收区. 例如, 仅仅在同 $\operatorname{Pr}^{3+}$ 离子的特征吸收峰相对应 的区域 $(430-480 \mathrm{~nm})$ 存在可检测的线性光伏电流.

表 1 列出了 $430 \mathrm{~nm}$ 附近的线性光伏电流和对应的 Glass 常数 $K_{\text {G. }} K_{G}$ 的大小与 Belinicher 提出的非铁电体离化杂质引起的线性光伏效应一致 ${ }^{[4]}$.

综上所述,最有意义的结果是: BGO 样品的光伏效应是由于 $\mathrm{Cr}$ 和 $\operatorname{Pr}$ 杂质引起的. 与 此相比较,纯净的 $\mathrm{BGO}$ 晶体和掺 $\mathrm{Pb}$ 的 BGO 中未发现可检测的线性光伏电流.

表 1 波长 $\lambda=430 \mathrm{~nm}$ 附近 BGO: $\mathrm{Cr}$ 和 BGO:Pr 的线性光伏电流及 Gless 常数

\begin{tabular}{c|c|c}
\hline 样 & 品 & 线性光伏电流 $\left(\mathrm{A} / \mathrm{cm}^{2}\right)$ \\
\hline BGO:Cr & $1.3 \times 10^{-14}$ & $6 \times 10^{-12}$ \\
\hline BGO:Pr & $2.4 \times 10^{-14}$ & $2.6 \times 10^{-12}$ \\
\hline
\end{tabular}

在一些氧八面体铁电体如 $\mathrm{LiNbO}_{3}, \mathrm{BaTiO}_{3}$ 等中的反常光伏效应, 可以用 Fridkin 提出 的极化涨落模型加以解释. 该理论对 BGO 也近似适用.

根据魏宗英的研究, BGO 中 $\mathrm{Cr}^{3+}$ 离子主要取代 $\mathrm{Ge}$ 位于氧四面体中[1. 另外, Moya 等 认为, $\mathrm{Cr}$ 离子以 $\mathrm{Cr}^{4+}$ 形式进人 $\mathrm{Ge}$ 位, 并可能作载流子陷阱 ${ }^{[6]}$. 这样, 可能发生如下空穴 过程:

$$
\begin{array}{ll}
\mathrm{Cr}^{4+} \longrightarrow \mathrm{Cr}^{3+}+\mathrm{h} & \text { (空穴产生), } \\
\mathrm{Cr}^{3+}+\mathrm{h} \longrightarrow \mathrm{Cr}^{3+} & \text { ( } \mathrm{Cr}^{3+} \text { 俘获空穴). }
\end{array}
$$

当用与杂质跃迁相对应的波长光照时, 在光照区会激发出空穴载流子, 并在晶格中移动, 随后 被陷获于新的位置上. 根据文献[7], 由杨-泰勒效应, 被陷获的载流子与棌光学声子相互作 用, 导致陷获位置附近光致极化涨落. 亦即导致宏观自发极化的改变 $\Delta P$, 产生局域场 $E \simeq$ $\Delta P / \varepsilon$ ( $\varepsilon$ 为介电系数), 从而导致样品中载流子的定向漂移, 产生光伏电流.

当然, 以上只是定性讨论了掺杂 BGO 晶体线性光伏效应的现象及可能解释. 随着对不 同掺杂浓度和不同杂质掺杂晶体的深入研究, 相信会得出更满意的结论.

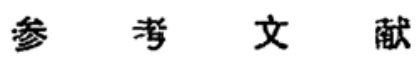

[1] Moys, E., J. Opt. Soc. Am.. B5(1988?, 1737.

[2] Fridkin, V. M., Appl. Phys., 13(1977), 357.

[3] Glass, A. M., Appl. Phys. Lett., 25(1974), 233.

[4] Belinicher, V. 1., Sturman. B. I., Sov. Phys. USP., 23(1980), 199.

[5] 魏宗英、何崇段之文, 无杖, 材料学报, 1990，5: 139.

[6] Moya, E. et al., Solid Siate Comm., 76(1990), 10.

[7] Chanussot, G., Ferroelectrics, 13(1976), 313. 